\title{
Evaluation of micellar properties of sodium dodecylbenzene sulphonate in the presence of some salts
}

\author{
ASHWANI KUMAR SOOD ${ }^{a, *}$ and MEENU AGGARWAL ${ }^{b}$ \\ ${ }^{a}$ Department of Chemistry, Guru Nanak Dev University, Amritsar, Punjab 143 005, India \\ ${ }^{b}$ Department of Mathematics, DAV College, Amritsar, Punjab 143 001, India \\ E-mail: aksoodchem@yahoo.co.in
}

MS received 30 November 2017; revised 27 February 2018; accepted 5 March 2018; published online 27 March 2018

\begin{abstract}
The influence of some salts $\left(\mathrm{NaCl}, \mathrm{KCl}, \mathrm{NH}_{4} \mathrm{Cl}\right.$ and $\left.\mathrm{MgCl}_{2}\right)$ on the critical micelle concentration (CMC) and fraction of counterion dissociation $(\alpha)$ of sodium dodecylbenzene sulphonate (SDBS) have been determined by conductometric and dynamic light scattering (DLS) methods at 298.15 K. The CMC determination involves fitting of experimental conductivity-surfactant concentration data into the integral form of Boltzmanntype sigmoidal equation. The procedure provides much better results compared to the conventional and differential methods for surfactant such as SDBS that exhibits a gradual transition from pre-micellar to the post-micellar region. The decrease in CMC of SDBS was found to be the highest in the presence of $\mathrm{MgCl}_{2}$ and least in the case of $\mathrm{NaCl}$ among the studied salts. The fraction of counter ion dissociation decreases sharply at lower concentrations of the salts (except $\mathrm{NaCl}$ ) which have been discussed in terms of effective ionic charge on the micelles. Using CMC and $\alpha$ value, the aggregation number of the micelle, micellar surface area and packing parameter has been calculated and were seen to agree well with the corresponding literature values obtained by using fluorescence and surface tension measurements. The effect of salts on the change in micellar size and the surface charge has also been evaluated with the help of DLS experiments and transmission electron microscopy (TEM) images.
\end{abstract}

Keywords. Sodium dodecylbenzene sulphonate; critical micelle concentration; salt effect; conductivity; dynamic light scattering.

\section{Introduction}

It is well-established that critical micelle concentration $(C M C)$ is the most significant parameter and is usually determined by the point of intersection of the two straight lines in conductivity-concentration plots. ${ }^{1-4}$ In such situations, the conductance is taken as directly proportionate to the concentration of the surfactant by ignoring the inter-ionic interactions. However, such procedures present difficulties for plots exhibiting weak curvatures, for instance, ionic surfactants in non-aqueous solvent systems. ${ }^{5,6}$ Therefore, in the present work, a more accurate method, proposed by Carpena et al., ${ }^{7}$ has been used to analyze conductivityconcentration data. It is based on fitting conductivity as a function of surfactant concentration to the integral form of Boltzmann equation as described in the Experimental section. The best fit provides the values of CMC and fraction of counter ion dissociation. This approach

\footnotetext{
*For correspondence
}

offers accurate results with less errors than the conventional, differential conductivity method for systems that exhibit a gradual transition from the pre-micellar to the post-micellar region.

The investigations on the micelle formation in the presence of salts are of special interest to the scientific world $^{8-14}$ as these salts form the basis of many chemical processes. The salts normally assist micelle formation and influence the energetics of the process. Further, in case of ionic surfactants, the effect of added salts on micellar behaviour is dependent on the counter ions. ${ }^{15,16}$

Although many studies have been devoted to the effect of commonly used salts on such behaviour, such reports on sodium dodecylbenzene sulphonate (SDBS) are rare. ${ }^{17-20}$ Moreover, the relative effect of different salts on micellar properties of SDBS is missing in these studies. In addition, many researchers have reported the fraction of counter ion dissociation $(\alpha)$ of the ionic micelles but there is no unified theory on the variation in $\alpha$ with salt concentration. These conflicting trends encouraged us to investigate the factors responsible for 
the behavior of SDBS solutions in the presence of different types of salts. The main objective of the study is a precise measurement of CMC and $\alpha$ value with the help of iterative method. These values have further been utilized to calculate aggregation number and surface area per head group of the micelles. Results thus obtained were found to be in good agreement with the literature reports. ${ }^{23}$

\section{Experimental}

\subsection{Chemicals}

The anionic surfactant SDBS (99\%) was obtained from Sigma Aldrich (USA) and used as such without further purification. All the salts $\mathrm{NaCl}$ (99.9\%), $\mathrm{NH}_{4} \mathrm{Cl}(99.0 \%), \mathrm{MgCl}_{2}(98.0 \%)$ and $\mathrm{KCl}(99.0 \%)$ were received from SD-Fine, Mumbai and recrystallized twice before use.

\subsection{Instruments and Methods}

2.2a Conductivity: The conductivity was measured using microprocessor-based conductivity meter (Systronics306, India). The solutions were kept at constant temperature $(298.15 \mathrm{~K})$ by circulating water through the glass jacket surrounding the conductivity cell. Double distilled or deionized water was used for the preparation of all the solutions. The $\mathrm{CMC}$ was determined by fitting the specific conductivity, $\kappa$, and [surfactant], $x$, to the following equation. ${ }^{17}$

$\kappa_{(x)}=\kappa_{(O)}+A_{1} x+\Delta x\left(A_{2}-A_{1}\right) \ln \frac{1+e^{\left(x-x_{o}\right) / \Delta x}}{1+e^{-x_{o} / \Delta x}}$

Here, the specific conductance of the solution is $\kappa_{(0)}$ when $x=0$; the pre- and post-micellar slopes are represented by $\mathrm{A}_{1}$ and $\mathrm{A}_{2}$, respectively, and the width of transition about central point, $x_{0}$, representing $\mathrm{CMC}$ is given as $\Delta x$. The data has been fitted by initially guessing the $\mathrm{A}_{1}, \mathrm{~A}_{2}, x_{0}$, and $\Delta x$ in Eq. 1 to obtain an approximate value of specific conductivity, ${ }^{\text {approx }} \kappa_{\mathrm{x}}$, corresponding to each surfactant concentration. Chisquare, $\chi^{2}$, has been defined as,

$\chi^{2}=\sum_{i=1}^{n}\left(\kappa_{\mathrm{i}}-{ }^{\text {approx }} \kappa_{\mathrm{x}}\right)^{2}$

Here, $\mathrm{n}$ is the number of data points, the experimental and approximate conductivity at a given total surfactant concentration are denoted by $\kappa_{i}$ and ${ }^{\text {approx }} \kappa_{i}$, respectively. The best estimate of the model parameters $\left(\mathrm{A}_{1}, \mathrm{~A}_{2}, x_{0}\right.$, and $\left.\Delta x\right)$ is given by the minimum value of $\chi^{2}$. Ionic micelles bind sufficient amount of counter ions in order to stabilize the selfaggregated surfactant system or the micelles by neutralizing the charge on the micelle. It lowers the intermicellar repulsion potential which results in a sharp decrease in $\kappa$ at the onset of micellization leading to the break in the $\kappa$ versus [surfactant] plot. The degree of counter ion dissociation $(\alpha)$ for ionic micelles is evaluated from the ratio of the postmicellar and premicellar slopes $\left(\alpha=A_{2} / A_{1}\right)$, following the procedure proposed by Evans. ${ }^{21}$ 2.2b Dynamic Light Scattering (DLS): The hydrodynamic diameter $\left(D_{h}\right)$ and zeta potential $(\zeta)$ were obtained from DLS measurements performed at $298.15 \mathrm{~K}$ on Zeta-Sizer Nano-ZS light scattering apparatus (Malvern Instruments, UK) equipped with $\mathrm{He}-\mathrm{Ne}$ laser in backscattering mode at a scattering angle of $173^{\circ}$. The samples were filtered using a membrane filter with a pore size of $450 \mathrm{~nm}$ in order to eliminate contamination.

2.2c Transmission Electron Microscopy (TEM): TEM imaging was carried out using a JEM-2100 electron microscope at a working voltage of $200 \mathrm{kV}$. A drop of a freshly prepared micellar solution of SDBS was placed on a carboncoated copper grid (300 mesh) and the residual solution was blotted out. The sample was then dried in air for $24 \mathrm{~h}$. Both DLS and TEM measurements were made on samples prepared with micellar solution at a concentration twice the observed CMC of the mixed system.

\section{Results and Discussion}

\subsection{Critical Micelle Concentration (CMC)}

The CMC value of SDBS was obtained from the $\kappa$ versus [SDBS] plots (Figure 1) as explained above and were seen to agree well with the literature. ${ }^{22,23}$ In order to obtain the effect of various salts on micellar properties, the CMC values in presence of these salts have also been determined and are presented in Table 1. The error in CMC measurement thus occurred was calculated to be $\pm 5 \times 10^{-2} \mathrm{mmol} \mathrm{dm}^{-3}$. For each salt, the dependence of $\mathrm{CMC}$ on [salt] was fitted using the following relation: ${ }^{24}$

$y=\frac{(a+b x)}{(1+c x)}$

Here, $\mathrm{y}$ is CMC and $\mathrm{x}$ is [salt] in mol $\mathrm{dm}^{-3}$. In the case of $\mathrm{NaCl}$, the experimental data has been fitted to the equation where,

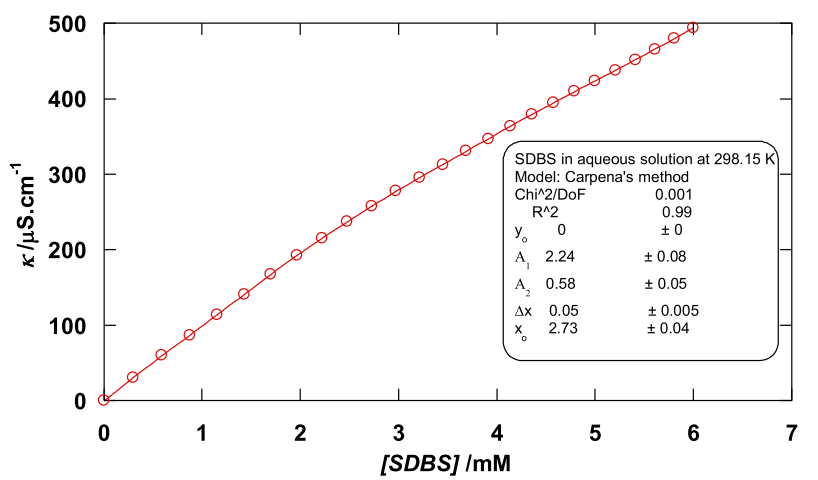

Figure 1. Specific conductance versus concentration plot (Fitted line) for SDBS at 298.15 K. 
Table 1. Micellization parameters of SDBS in presence of salts at $298.15 \mathrm{~K}$.

\begin{tabular}{|c|c|c|c|c|}
\hline Salt & {$[$ Salt $] / \mathrm{mM}$} & $\mathrm{CMC} / \mathrm{mM}$ & $\alpha$ & $\lambda_{o}^{-} / \mathrm{S} \mathrm{cm}^{-2} \mathrm{~mol}^{-1}$ \\
\hline \multirow[t]{9}{*}{$\mathrm{NaCl}$} & 0.00 & $2.73 \pm 0.04(2.58)^{\mathrm{a}}(2.90)^{\mathrm{b}}$ & $0.52 \pm 0.06$ & $138.45 \pm 0.79$ \\
\hline & 0.50 & $2.14 \pm 0.04$ & $0.55 \pm 0.04$ & $143.68 \pm 0.82$ \\
\hline & 1.00 & $1.78 \pm 0.02$ & $0.58 \pm 0.07$ & $152.14 \pm 0.67$ \\
\hline & 2.00 & $1.62 \pm 0.04$ & $0.60 \pm 0.03$ & $154.37 \pm 0.32$ \\
\hline & 3.00 & $1.53 \pm 0.03$ & $0.63 \pm 0.04$ & $163.49 \pm 0.88$ \\
\hline & 4.00 & $1.47 \pm 0.05$ & $0.61 \pm 0.06$ & $158.47 \pm 0.96$ \\
\hline & 5.00 & $1.42 \pm 0.01$ & $0.56 \pm 0.05$ & $150.32 \pm 1.02$ \\
\hline & 7.50 & $1.37 \pm 0.02$ & $0.49 \pm 0.04$ & $147.61 \pm 1.04$ \\
\hline & 10.00 & $1.34 \pm 0.03$ & $0.38 \pm 0.04$ & $144.94 \pm 0.76$ \\
\hline \multirow[t]{8}{*}{$\mathrm{NH}_{4} \mathrm{Cl}$} & 0.50 & $1.91 \pm 0.04$ & $0.44 \pm 0.02$ & $129.64 \pm 0.58$ \\
\hline & 1.00 & $1.60 \pm 0.03$ & $0.37 \pm 0.04$ & $120.33 \pm 0.62$ \\
\hline & 2.00 & $1.47 \pm 0.02$ & $0.39 \pm 0.03$ & $117.46 \pm 0.47$ \\
\hline & 3.00 & $1.40 \pm 0.05$ & $0.47 \pm 0.05$ & $131.25 \pm 0.88$ \\
\hline & 4.00 & $1.31 \pm 0.01$ & $0.53 \pm 0.03$ & $146.62 \pm 0.64$ \\
\hline & 5.00 & $1.25 \pm 0.03$ & $0.55 \pm 0.04$ & $151.44 \pm 0.96$ \\
\hline & 7.50 & $1.20 \pm 0.04$ & $0.46 \pm 0.04$ & $138.57 \pm 0.97$ \\
\hline & 10.00 & $1.16 \pm 0.02$ & $0.41 \pm 0.06$ & $129.61 \pm 1.02$ \\
\hline \multirow[t]{8}{*}{$\mathrm{MgCl}_{2}$} & 0.50 & $1.54 \pm 0.03$ & $0.59 \pm 0.05$ & $162.14 \pm 0.76$ \\
\hline & 1.00 & $1.31 \pm 0.02$ & $0.41 \pm 0.07$ & $155.47 \pm 0.58$ \\
\hline & 2.00 & $1.22 \pm 0.01$ & $0.36 \pm 0.03$ & $146.38 \pm 0.37$ \\
\hline & 3.00 & $1.10 \pm 0.01$ & $0.33 \pm 0.04$ & $139.74 \pm 0.48$ \\
\hline & 4.00 & $1.01 \pm 0.02$ & $0.29 \pm 0.04$ & $133.21 \pm 0.95$ \\
\hline & 5.00 & $0.96 \pm 0.02$ & $0.30 \pm 0.06$ & $122.25 \pm 0.84$ \\
\hline & 7.50 & $0.93 \pm 0.02$ & $0.48 \pm 0.02$ & $147.96 \pm 0.67$ \\
\hline & 10.00 & $0.90 \pm 0.03$ & $0.57 \pm 0.07$ & $164.54 \pm 0.98$ \\
\hline \multirow[t]{8}{*}{$\mathrm{KCl}$} & 0.50 & $1.77 \pm 0.04$ & $0.51 \pm 0.05$ & $157.49 \pm 0.63$ \\
\hline & 1.00 & $1.41 \pm 0.02$ & $0.34 \pm 0.03$ & $144.62 \pm 0.54$ \\
\hline & 2.00 & $1.31 \pm 0.03$ & $0.27 \pm 0.04$ & $132.47 \pm 0.87$ \\
\hline & 3.00 & $1.25 \pm 0.02$ & $0.47 \pm 0.02$ & $138.96 \pm 1.06$ \\
\hline & 4.00 & $1.16 \pm 0.02$ & $0.55 \pm 0.05$ & $142.78 \pm 1.02$ \\
\hline & 5.00 & $1.12 \pm 0.01$ & $0.59 \pm 0.04$ & $155.04 \pm 0.99$ \\
\hline & 7.50 & $1.10 \pm 0.02$ & $0.61 \pm 0.05$ & $149.63 \pm 0.86$ \\
\hline & 10.00 & $1.08 \pm 0.03$ & $0.63 \pm 0.04$ & $164.28 \pm 0.85$ \\
\hline
\end{tabular}

${ }^{\mathrm{a}} \operatorname{Ref}[22] ;{ }^{\mathrm{b}} \operatorname{Ref}[23]$.

$\mathrm{a}=0.0079 \pm 0.0003, \mathrm{~b}=0.0543 \pm 0.0079$ and

$\mathrm{c}=76.04 \pm 4.23\left(\mathrm{R}^{2}=0.996\right)$

For all the other salts, values of coefficients are:

$$
\begin{aligned}
& \mathrm{NH}_{4} \mathrm{Cl}: \mathrm{a}=0.0075 \pm 0.0005, \mathrm{~b}=0.0474 \pm \\
& 0.0143, \mathrm{c}=95.27 \pm 7.63\left(\mathrm{R}^{2}=0.995\right) \\
& \mathrm{KCl}: \mathrm{a}=0.0084 \pm 0.0003, \mathrm{~b}=-0.2692 \pm \\
& 0.0634, \mathrm{c}=84.68 \pm 6.89\left(\mathrm{R}^{2}=0.991\right) \\
& \mathrm{MgCl}_{2}: \mathrm{a}=0.0076 \pm 0.0002, \mathrm{~b}=1.7321 \pm \\
& 0.3194, \mathrm{c}=2184 \pm 43\left(\mathrm{R}^{2}=0.989\right)
\end{aligned}
$$

In the presence of salts with different cations, the CMC of SDBS decreases as the salt is added in aqueous SDBS solution which is due to the compression of the electric double layer at the interface due to electrostatic interactions. This facilitates the adsorption of surfactant molecules at the interface and thus reduces the CMC. ${ }^{21-23}$ Among the various salts, the CMC of SDBS follows the sequence: $\mathrm{MgCl}_{2}<\mathrm{KCl}<\mathrm{NH}_{4} \mathrm{Cl}<$ $\mathrm{NaCl}$ as shown in Figure 2. It can be explained by considering the ratio of valence $(Z)$ and van der Waals radius $(R), Z / R$. The cations having larger $Z / R$ value are more hydrated and water structure makers. ${ }^{16}$ These ions tend to decrease the CMC values more as they possess a strong ability to salt out the hydrophobic groups of the surfactant from the aqueous phase. Since $Z / R$ value is maximum (9.62) for divalent $\mathrm{Mg}^{2+}$ ions and lowest (4.35) for $\mathrm{Na}^{+}$among monovalent ions, ${ }^{13}$ the decrease in $\mathrm{CMC}$ is highest in the presence of $\mathrm{MgCl}_{2}$ and the least for $\mathrm{NaCl}$.

\subsection{Influence of different salts on $\alpha$}

The decrease or increase in $\alpha$ value (Table 1 ) for different salts varies with the type and composition of the salts. In case of $\mathrm{Na}^{+}$ions, $\alpha$ value initially increases 


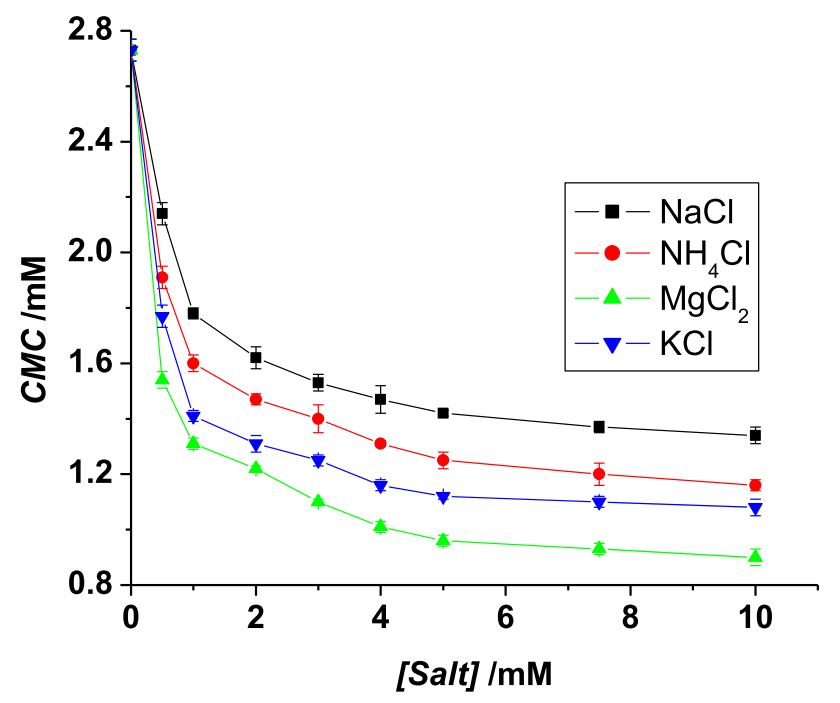

Figure 2. Effect of salts on the CMC of SDBS. Drawn lines are guide to the eye.

with [salt] and then starts to decrease after reaching a maximum (Figure 3). The initial increase in $\alpha$ at low concentrations is either due to the micellar growth or increase in the screening of the charge. ${ }^{25}$ This increase in the micellar size would result in a decrease in the charge density causing the release of the counter ions. ${ }^{24}$ At higher concentrations (7.5 and $10 \mathrm{mM})$ of $\mathrm{Na}^{+}$ion, the $\alpha$ values decrease due to binding of a large number of counter ions to the micellar surface, resulting in a decrease in $\alpha$ value $^{26}$ in aqueous solutions possessing high ionic strength. In case of $\mathrm{NH}_{4}^{+}$ions, the $\alpha$ value decreases initially; after reaching a minimum, the value starts to increase and then decreases at higher [salt] similar to that for $\mathrm{Na}^{+}$ion. However, for $\mathrm{Mg}^{2+}$ and $\mathrm{K}^{+}$ions, the effective ionic charge is the highest among the studied cations. Therefore, the decrease in $\alpha$ value is sharp at low salt concentrations. Hence, the CMC of SDBS decreases drastically in the presence of $\mathrm{Mg}^{2+}$ and $\mathrm{K}^{+}$in comparison to $\mathrm{NH}_{4}^{+}$and $\mathrm{Na}^{+}$ions.

The $\alpha$ values decrease at lower concentrations of the studied salts (except $\mathrm{NaCl}$ ) which can be attributed to the strong interactions of SDBS micelles with $\mathrm{Mg}^{2+}, \mathrm{K}^{+}$ and $\mathrm{NH}_{4}^{+}$in comparison to $\mathrm{Na}^{+}$ion. Among the studied cations, the net ionic charge is more in the case of $\mathrm{Mg}^{2+}$ ions even though the hydration of these ions is the highest. Thus, the decrease in $\alpha$ value among the cations follow the sequence: $\mathrm{Mg}^{2+}>\mathrm{K}^{+}>\mathrm{NH}_{4}^{+}$. In case of $\mathrm{NaCl}$, the $\alpha$ value increases at lower concentrations because $\mathrm{Na}^{+}$ions are more screened as compared to $\mathrm{K}^{+}$and $\mathrm{NH}_{4}^{+}$ions as the hydration of $\mathrm{Na}^{+}$ions is more than that $\mathrm{K}^{+}$and $\mathrm{NH}_{4}^{+}$ions. Further, the $\mathrm{CMC}$ values of SDBS decrease drastically in the presence of $\mathrm{Mg}^{2+}$ and

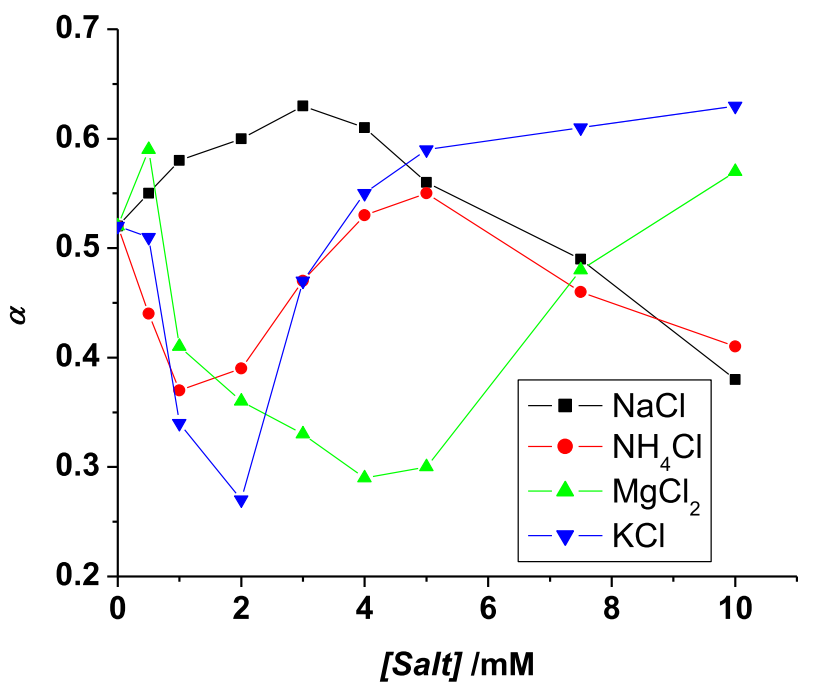

Figure 3. Effect of salts on $\alpha$ values for SDBS. Lines drawn are guide to the eye.

$\mathrm{K}^{+}$in comparison to that of $\mathrm{Na}^{+}$and $\mathrm{NH}_{4}^{+}$ions (Figure 2) as the effective ionic charge on $\mathrm{Mg}^{2+}$ and $\mathrm{K}^{+}$ ions are the highest among the studies of electrolytes.

\subsection{Influence of various salts on derived parameters}

The aggregation number $(\mathrm{N})$ for SDBS has been calculated as, ${ }^{27}$

$N=K\left(\left[\text { Counterion }^{+}\right]_{a q}\right)^{\gamma}$

Where, $\left[\text { Counterion }^{+}\right]_{a q}$ represents the composition of counter ions (in moles) supplied by both added salts and SDBS. $K$ and $\gamma$ are constants that depend upon the length of the alkyl chain ${ }^{28}$ and their values for SDBS are 158 and 0.16 , respectively. The term [ Counterion $\left.^{+}\right]_{a q}$ is given by the following relationship: ${ }^{27}$

$$
\begin{aligned}
\text { Counterion } \left.^{+}\right]_{a q}= & \alpha[S D B S]+(1-\alpha) C M C \\
& +[\text { salt }]
\end{aligned}
$$

The values of $N$ thus obtained are presented in Table 2 and agree well with those obtained using fluorescence measurements. ${ }^{23}$ Since the electrostatic repulsions between the head groups decrease in the presence of salt ${ }^{11}$, therefore, the $\mathrm{N}$ values increase with [salt] and this increase is more in the presence of $\mathrm{Na}^{+}$ions. The radius of the micelle, $r$, has been obtained from, ${ }^{29}$

$r=\left[\frac{3}{4 \pi}\left(27.4+26.9 n_{c}\right) N\right]^{1 / 3}$

Here, the number of carbon atoms per hydrocarbon chain of the surfactant is exhibited by $n_{c}$. Since the values of $r$ are directly proportional to $N$, hence, these values also increase with [salt]. From the knowledge of 
Table 2. Aggregation number $(\mathrm{N})$, surface area per head group $\left(\mathrm{A}_{\mathrm{o}}\right)$, packing parameter $\left(\mathrm{P}_{\mathrm{m}}\right)$, volume per surfactant molecule $\left(\mathrm{V}_{\mathrm{P}}\right)$, hydrodynamic diameter $\left(D_{h}\right)$ and zeta potential $(\zeta)$ for SDBS at $298.15 \mathrm{~K}$.

\begin{tabular}{|c|c|c|c|c|c|c|c|}
\hline Salt & {$[$ Salt $] / \mathrm{mM}$} & $\mathrm{N}$ & $\mathrm{A}_{\mathrm{o}} / \AA^{2}$ & $\mathrm{P}_{\mathrm{m}}$ & $\mathrm{V}_{\mathrm{p}} / \AA^{3}$ & $\mathrm{D}_{\mathrm{h}} / \mathrm{nm}$ & $\zeta / \mathrm{mV}$ \\
\hline \multirow[t]{9}{*}{$\mathrm{NaCl}$} & 0.00 & $57(61)^{\mathrm{c}}$ & $78(74)^{\mathrm{c}}$ & 0.31 & 557.23 & 2.9 & -82.1 \\
\hline & 0.50 & 65 & 71 & 0.33 & 458.62 & 3.2 & -64.4 \\
\hline & 1.00 & 69 & 65 & 0.35 & 423.58 & 3.3 & -68.2 \\
\hline & 2.00 & 72 & 61 & 0.36 & 411.25 & 4.3 & -55.1 \\
\hline & 3.00 & 73 & 59 & 0.38 & 372.66 & 6.6 & -50.4 \\
\hline & 4.00 & 76 & 54 & 0.40 & 352.84 & 8.7 & -45.6 \\
\hline & 5.00 & 79 & 52 & 0.41 & 338.91 & 12.9 & -47.9 \\
\hline & 7.50 & 71 & 49 & 0.37 & 296.55 & 18.3 & -43.8 \\
\hline & 10.00 & 59 & 44 & 0.36 & 244.68 & 27.8 & -43.2 \\
\hline \multirow[t]{8}{*}{$\mathrm{NH}_{4} \mathrm{Cl}$} & 0.50 & 59 & 75 & 0.32 & 476.57 & 3.2 & -63.1 \\
\hline & 1.00 & 61 & 71 & 0.32 & 463.09 & 3.5 & -68.5 \\
\hline & 2.00 & 64 & 68 & 0.33 & 452.16 & 4.7 & -51.2 \\
\hline & 3.00 & 68 & 65 & 0.35 & 439.27 & 6.7 & -48.8 \\
\hline & 4.00 & 71 & 62 & 0.34 & 416.85 & 11.0 & -45.2 \\
\hline & 5.00 & 73 & 60 & 0.35 & 391.62 & 17.5 & -46.5 \\
\hline & 7.50 & 68 & 56 & 0.36 & 365.08 & 26.1 & -42.1 \\
\hline & 10.00 & 61 & 52 & 0.38 & 331.26 & 34.9 & -41.6 \\
\hline \multirow[t]{8}{*}{$\mathrm{MgCl}_{2}$} & 0.50 & 58 & 75 & 0.33 & 523.68 & 3.8 & -55.3 \\
\hline & 1.00 & 59 & 70 & 0.34 & 504.24 & 4.2 & -47.2 \\
\hline & 2.00 & 62 & 68 & 0.34 & 473.82 & 4.7 & -41.4 \\
\hline & 3.00 & 64 & 66 & 0.35 & 462.51 & 5.9 & -38.7 \\
\hline & 4.00 & 65 & 65 & 0.34 & 437.66 & 8.6 & -33.2 \\
\hline & 5.00 & 63 & 62 & 0.37 & 392.87 & 19.9 & -32.1 \\
\hline & 7.50 & 58 & 58 & 0.35 & 374.62 & 25.4 & -31.7 \\
\hline & 10.00 & 62 & 55 & 0.37 & 335.84 & 45.6 & -28.2 \\
\hline \multirow[t]{8}{*}{$\mathrm{KCl}$} & 0.50 & 59 & 74 & 0.34 & 489.52 & 3.5 & -58.4 \\
\hline & 1.00 & 62 & 72 & 0.33 & 471.06 & 3.9 & -47.6 \\
\hline & 2.00 & 64 & 71 & 0.35 & 445.38 & 4.9 & -48.9 \\
\hline & 3.00 & 63 & 65 & 0.36 & 411.27 & 6.8 & -43.2 \\
\hline & 4.00 & 68 & 60 & 0.34 & 381.66 & 10.2 & -40.3 \\
\hline & 5.00 & 71 & 56 & 0.35 & 348.57 & 18.6 & -38.2 \\
\hline & 7.50 & 77 & 52 & 0.35 & 326.54 & 28.7 & -36.6 \\
\hline & 10.00 & 84 & 47 & 0.37 & 286.35 & 39.4 & -35.1 \\
\hline
\end{tabular}

${ }^{\mathrm{c}} \operatorname{Ref}[23]$.

$r$, the micellar surface area per head group $\left(A_{o}\right)$ may be found using, ${ }^{30}$

$$
A_{o}=\frac{3 v}{r}
$$

$v$ is the volume corresponding to the hydrophobic chain of the micelle ${ }^{31}$ and is given by $v=27.4+26.9 n_{c} \AA^{3} \cdot A_{o}$ value in aqueous solution of SDBS is understandably higher (Table 2) than the value of minimum area $\left(\mathrm{A}_{\min }\right)$ reported in the literature. ${ }^{23}$ These values decrease with increase in [salt] due to close packing of the adsorbed molecules as a consequence of better screening of the head groups in presence of salts. ${ }^{11}$ The packing parameter, $P_{m}$, has been calculated as,

$$
P_{m}=\frac{v}{A_{o} l}
$$

$l=1.5+1.265 n_{c}$ and represents the hydrophobic chain length. For spherical micelles, $P_{m}=0.33$; cylindrical micelles $P_{m}=0.50$ and for disks and bilayers, $P_{m}=$ 1. Generally, $P_{m}$ is calculated by taking $\mathrm{A}_{\min }$ value as an approximation to $A_{o}$ value. But, we have estimated the accurate values of $P_{m}$ using $A_{o}$. From Table 2, it can be seen that $P_{m}$ value increases slightly with [salt] indicating formation of larger micelles. The volume of each molecule of surfactant in the shell of the micelle $\left(V_{P}\right)$ has been obtained as, ${ }^{28}$

$\left.V_{P}=\frac{4 \pi}{3 N}\left[(r+5)^{3}-r^{3}\right)\right]$

The calculated value of $V_{P}$ (Table 2) decreases with the increase in [salt] and the decrease is more in the case of $\mathrm{NaCl}$. The limiting ionic equivalent conductance for SDBS micelles $\left(\lambda_{o}^{-}\right)$has also been evaluated using 

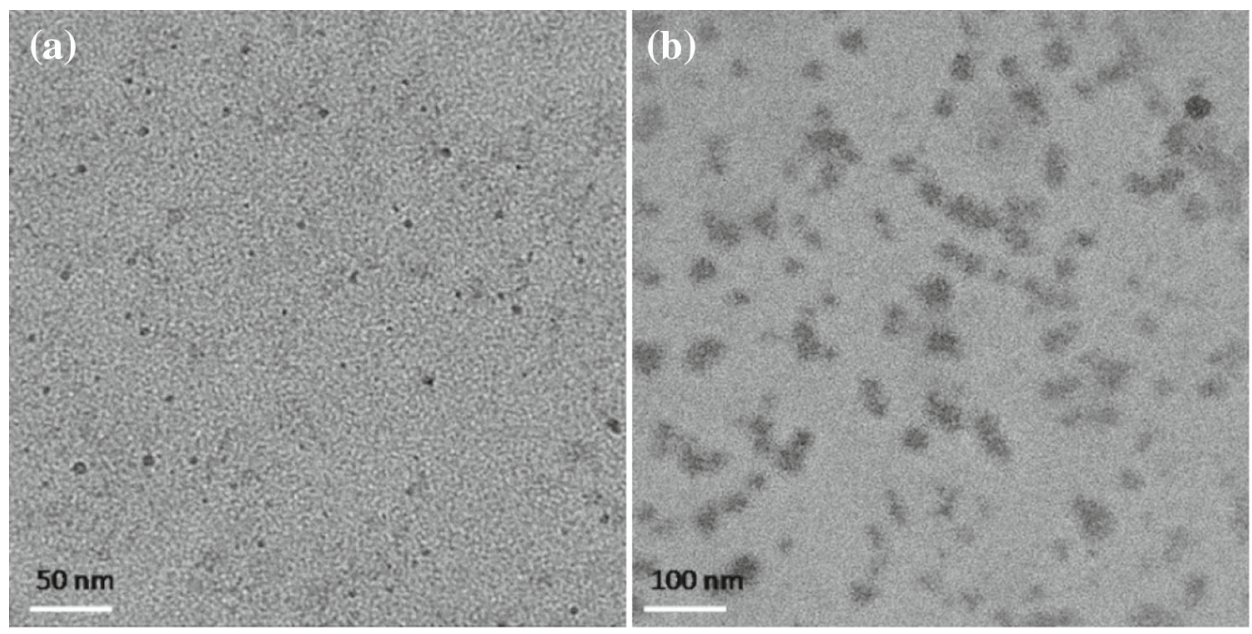

Figure 4. TEM image of SDBS micelles in (Left) aqueous solution; (Right) $10 \mathrm{mM} \mathrm{NaCl}$ solution.

Stokes-Einstein equation. ${ }^{25}$

$\lambda_{o}^{-}=\frac{N \alpha e_{o} F}{6 \pi \eta r}$

Here, $\eta$ is the viscosity of water; $F$ is the Faraday constant and $e_{o}$ is the charge. In the presence of the studied salts, the value of $\lambda_{o}^{-}$for SDBS micelles changes differently with [salt] as the charge $(N \alpha)$ depends upon the kind and [salt] added. Hence, $\lambda_{o}^{-}$decreases and increases in the same range of [salt] as $\alpha$.

\subsection{Hydrodynamic diameter and Zeta potential}

DLS experiments were performed to measure the hydrodynamic diameter $\left(D_{h}\right)$ of SDBS micelles in aqueous solutions of different salts. $\mathrm{D}_{\mathrm{h}}$ for SDBS micelles (without salt) is $2.9 \mathrm{~nm}$ which is lower than $3.4 \mathrm{~nm}$ obtained previously for SDS micelles ${ }^{32}$ although both the surfactants have the same dodecyl chain in their monomers. It can be understood based on the fact that SDBS monomer has one extra benzene ring. As a consequence, the head groups cannot come close beyond a certain limit due to the repulsive interactions of the $\pi$-electron cloud of the benzene ring present at the micellar surface. Therefore, the hydrocarbon chain of SDBS acquires folded confirmation and hence $D_{h}$ of SDBS is expected to be less than that of SDS.

The increase in $D_{h}$ of SDBS micelles with [salt] is due to an increase in electrostatic repulsion between the head groups as shown clearly in the TEM image (Figure 4). However, the increase in $D_{h}$ is not much at lower [salt] but beyond $5 \mathrm{mM}$, the size of SDBS aggregate increases suddenly, which is an indication of the shape change as confirmed by $\mathrm{P}_{\mathrm{m}}$ values. The magnitude of zeta potential $(\zeta)$ provides a measure of the stability of the colloidal system. The negative values of $\zeta$ is due to the charge on SDBS micelles. The magnitude of $\zeta$ decreases with increasing [salt] as a result of a decrease in thickness of the electric double layer (Gouy-Chapman layer). Both $\mathrm{D}_{h}$ and $\zeta$ values supplement the observations from conductivity measurements.

\section{Conclusions}

A precise and iterative method has been used to study the influence of some salts on the CMC and fraction of counter ion dissociation of SDBS in aqueous solutions. All the studied salts decrease the CMC of SDBS according to the sequence: $\mathrm{MgCl}_{2}<\mathrm{KCl}<\mathrm{NH}_{4} \mathrm{Cl}<$ $\mathrm{NaCl}$ which has been attributed to the difference in their charge to radius ratio. The aggregation number increases whereas surface area per head group decreases with [salt]. DLS studies exhibit an increase in $\mathrm{D}_{\mathrm{h}}$ upon addition of salts which is further confirmed by TEM images. The $\zeta$ values were negative whose magnitude decreases in the presence of salts due to the decrease in the thickness of the electric double layer. The limiting equivalent conductance of SDBS micelles is more in the presence of $\mathrm{Na}^{+}$and $\mathrm{K}^{+}$in comparison to $\mathrm{NH}_{4}^{+}$ and $\mathrm{Mg}^{2+}$ ions.

\section{References}

1. Dubey N 2013 CTAB aggregation in solutions of higher alcohols: Thermodynamic and spectroscopic studies $J$. Mol. Liq. 18460

2. Kaushal D, Rana D S, Chauhan M S and Chauhan S 2013 A physicochemical study of SDS in aqueous solution of Furosemide: Effect of DMSO on surfactant-Furosemide interaction Fluid Phase Equilibr. 355123 
3. Sood A K, Singh K, Kaur J and Banipal T S 2012 Mixed micellization behavior of $\mathrm{m}$-2-m gemini surfactants with some conventional surfactants at different temperatures J. Surfact. Deterg. 15327

4. Banipal T S and Sood A K 2014 Effect of hydrophobicity and temperature on mixed micellar interactions of F68 and P123 with monomeric and dimeric surfactants J. Surfact. Deterg. 171169

5. Ruiz C C 1999 Thermodynamics of micellization of tetradecyltrimethylammonium bromide in ethylene glycol + water binary mixtures Colloid Polym. Sci. 277701

6. Ruiz C C 1999 Micelle formation and microenvironmental properties of sodium dodecyl sulfate in aqueous urea solutions Colloids Surf. A 147349

7. Carpena P, Aguiar J, Bernaola-Galvan P and Ruiz C C 2002 Problems associated with the treatment of conductivity-concentration data in surfactant solutions:?Simulations and Experiments Langmuir 186054

8. Swanson-Vethamuthu M, Almgren M, Hansson P and Zhao J 1996 Surface tension studies of cetyltrimethylammonium bromide-bile salt association Langmuir $\mathbf{1 2}$ 2186

9. Maiti K, Bhattacharya S C, Moulik S P and Panda A K 2010 Physicochemical studies on ion-pair amphiphiles: Solution and interfacial behaviour of systems derived from sodium dodecylsulfate and nalkyltrimethylammonium bromide homologues J. Chem. Sci. 122867

10. Chauhan S, Kaur M, Kumar K and Chauhan M S 2014 Study of the effect of electrolyte and temperature on the critical micelle concentration of dodecyltrimethylammonium bromide in aqueous medium J. Chem. Thermody. 78175

11. Ray G B, Ghosh S and Moulik S P 2010 Ternary mixtures of alkyltriphenylphosphonium bromides $\left(\mathrm{C}_{12} \mathrm{TPB}\right.$, $\mathrm{C}_{14} \mathrm{TPB}$ and $\mathrm{C}_{16} \mathrm{TPB}$ ) in aqueous medium: their interfacial, bulk and fluorescence quenching behavior J. Chem. Sci. 122109

12. Kroflič A, Šarac B and Bešter-Rogac M Influence of the alkyl chain length, temperature and added salt on the thermodynamics of micellization: Alkyltrimethylammonium chlorides in $\mathrm{NaCl}$ aqueous solutions J. Chem. Thermody. 431557

13. Ren Z H 2015 Mechanism of the salt effect on micellization of an aminosulfonate amphoteric surfactant Ind. Eng. Chem. Res. 549683

14. Naskar B, Dey A and Moulik S P 2013 Counter-ion effect on micellization of ionic surfactants:A comprehensive understanding with two representatives, Sodium Dodecyl Sulfate (SDS) and Dodecyltrimethylammonium Bromide (DTAB) J. Surfact. Deterg. 16785

15. Akram M, Bhat I A and Kabir-ud-Din 2015 Self aggregation of surfactant Ethane-1,2-diyl bis(N,NdimethylNhexadecylammoniumacetoxy)

Dichloride: Tensiometric, microscopic and spectroscopic studies J. Phys. Chem. B 1193499

16. Akram M, Bhat I A and Kabir-ud-Din 2016 Effect of salt counterions on the physicochemical characteristics of novel green surfactant, ethane-1,2-diylbis(N,Ndimethyl-N-tetradecylammoniumacetoxy) dichloride Colloids Surf. A 49332
17. Kumar S, Sharma D and Kabir-ud-Din 2002 Micellization of sodium dodecylbenzene sulphonate in aqueous quaternary bromide J. Surf. Sci. Tech. 1825

18. Cheng D C H and Gulari E 1982 Micellization and intermicellar interactions in aqueous sodium dodecyl benzene sulfonate solutions J. Colloid Interface Sci. 90 410

19. Krznarić D, Filipović-Vinceković N, Babić-Ivančić V and Bilinski H 1997 Interactions of sodium dodecylbenzenesulfonate and calcite in $0.55 \mathrm{M} \mathrm{NaCl}$ solution Croat. Chem. Acta 7095

20. Tyowua A T, Yiase S G and Wuanna R A 2012 Manipulation of concentration-conductivity data of sodium dodecyl sulphate and sodium dodecylbenzene sulphonate in $\mathrm{KCl}$ solution in relation to micellization parameters $J$. Chem. Sci. 793

21. Evans H C 1956 117. Alkyl sulphates. Part I. Critical micelle concentrations of the sodium salts J. Chem. Soc. 579

22. Dubey N 2009 Thermodynamic Properties of micellization of sodium dodecylbenzene sulfonate in the aqueousrich region of 1-pentanol and 1-hexanol J. Chem. Eng. Data 541015

23. Hait S K, Majhi P R, Blume A and Moulik S P 2003 A critical assessment of micellization of sodium dodecyl benzene sulfonate (SDBS) and its interaction with poly(vinyl pyrrolidone) and hydrophobically modified polymers; JR 400 and LM 200 J. Phys. Chem. B 107 3650

24. Dutkiewicz E and Jakubowska A 2002 Effect of electrolytes on the physicochemical behaviour of sodium dodecyl sulphate micelles Colloid Polym. Sci. 280 1009

25. Shanks P C and Franses E I 1992 Estimation of micellization parameters of aqueous sodium dodecyl sulfate from conductivity data J. Phys. Chem. 961794

26. Nagarajan R and Ruckenstein E 1979 Aggregation of amphiphiles as micelles or vesicles in aqueous media $J$. Colloid Interface Sci. 71580

27. Ranganathan R, Peric M and Bales B L 1998 TimeResolved Fluorescence Quenching measurements of the aggregation numbers of normal sodium alkyl sulfate micelles well above the critical micelle concentrations J. Phys. Chem. B $\mathbf{1 0 2} 8436$

28. Bales B L, Vidal L M A and Peric M 1998 Precision relative aggregation number determinations of SDS micelles using a spin probe, a model of micelle surface hydration. J. Phys. Chem. B 10210347

29. Tanford C 1973 In The hydrophobic effect: Formation of micelles and biologicalmembranes (New York: WileyInterscience) p. 146

30. Briganti G, Puvvada S and Blankstein D 1991 Effect of urea on micellar properties of aqueous solutions of nonionic surfactants J. Phys. Chem. 958989

31. Sood A K, Kaur H and Banipal T S Interactions in the mixed micelles of monomeric and gemini surfactants: Influence of some co-solvents as a function of temperature Arab. J. Chem. In press.

32. Mata J, Varade D, Ghosh G, Bahadur P 2004 Effect of tetrabutylammonium bromide on the micelles of sodium dodecyl sulfate Colloids Surf. A 24569 